\title{
Ethical dilemma: do not resuscitate a vegetative paediatric patient
}

\author{
Wong Pik Yan Pat RN; BN, Registered Nurse, Prince of Wales Hospital, Hong Kong. \\ Lorna Kwai Ping Suen RN, RM; MPH, PhD, Associate Professor, The Nethersole School of Nursing, The Chinese University of \\ Hong Kong, Hong Kong. \\ Sek Ying Chair RN; MBA, PhD, Associate Professor, The Nethersole School of Nursing, The Chinese University of Hong Kong, \\ Hong Kong.
}

Key Words: do not resuscitate $*$ end of life $*$ intensive care $*$ paediatric $*$ persistent vegetative state

E-mail: sychair@cuhk.edu.hk

ESPAÑOL
Dilema ético: no reanimar a un paciente pediátrico en estado
vegetativo
Palabras clave
No reanimar, fin de vida, cuidado intensivo, pediátrico, estado
vegetativo persistente
Resumen
Durante el período final de la vida permitir al paciente morir
puede ser compasivo al evitar sufrimiento innecesario.
Cuando el tratamiento es fútil, no hay obligación de tratar.
Los deseos del paciente deben ser considerados de alta
prioridad en las decisiones de no reanimar.
Los principios de beneficencia, no maleficencia, autonomía
y justicia deben guiar el cuidado en el final de la vida.

\section{SUMMARY}

- During the end-of-life period, allowing patients to die may be beneficent to prevent unnecessary suffering.

- When treatment is futile, there is no obligation to treat.

- The patient's wish should be considered as the highest priority in do not resuscitate decisions.

- The principles of beneficence, nonmaleficence, autonomy and justice should guide the end-of-life care.

\section{INTRODUCTION}

With the advances in health care technology, nurses have become increasingly involved in the care of patients with a do not resuscitate (DNR) order. A trend in the increase in and wider application of DNR status has become evident (Costello, 2002; Daly et al., 1996; Simpson, 1994; Yap, Joynt \& Gomersall, 2004). Thus, the likelihood of critical care nurses being exposed to patients designated as DNR is significant.

Technological advances are challenging the way health care is delivered and the nursing profession is being constantly confronted by ethical dilemmas. Ethics has been defined as the recognised rules of conduct with respect to a particular class of human (Dunn, 1998). A dilemma is a choice, of whatever kind, between two equally unsatisfactory alternatives (Thompson, Melia, Boyd \& Horsburgh, 2006).

In recent years, the number of critically ill children admitted to the paediatric intensive care unit (PICU) that become permanent vegetative patients is increasing. The consideration of DNR in vegetative patients raises a great concern. The following case is quoted to discuss the ethical dilemma in the DNR order. Ethical theories, the principles of beneficence, nonmaleficence, autonomy and justice, as well as the legal considerations will be explored. Nurses are left with implications and gain more insights in DNR decision.

\section{The case study}

Tom (a pseudonym), a 12-year old boy, had cerebral palsy, scoliosis, and was mentally retarded. Premorbid status was chair bound, on nappy, able to take congee or cereals only and said only a few single words. He was admitted to the PICU after an episode of cardiac arrest due to aspiration. He was resuscitated in 42 minutes and finally survived with an irreversible coma. One month later, due to severe hypoxic brain damage, he remained in vegetative state and dependent on the ventilator with no spontaneous breathing nor movement. From the medical point of view, there was almost no chance of recovery. Resuscitation only caused more suffering to him and would not affect the outcome. The doctors and his parents hence agreed on a DNR order for Tom in case of cardiac arrest again. The parents were given the explanation regarding the child's condition, the rationale of DNR, and the right to change the decision at anytime.

Four months later, he developed major desaturation which could not be settled by tracheal suction and increased oxygen concentration. Doctor and parents were informed. Tom then progressively developed cardiac arrest. In view of the present DNR, cardiopulmonary resuscitation (CPR) was not initiated, and Tom passed away subsequently.

\section{Do not resuscitate order}

"DNR" is a written medical order stating that cardiopulmonary resuscitative measures will not be initiated in the event of a cardiac or respiratory arrest (Roth \& Corrigan, 2005). 
The doctor will discuss the prognosis or DNR with the patient or his family when indicated. Patient's rights will be respected when decisions are made to withhold resuscitative services. The doctor will document the DNR order in detail. Nurses will initiate CPR when indicated unless the patient is designated as DNR. A DNR order is revocable by the patient (Roth \& Corrigan, 2005).

\section{ETHICAL THEORY}

\section{Beneficence}

Beneficence means "to always do good" (Hendrick, 2000), in which a moral agent ought to promote the welfare of others, involving the removal of harm, the prevention of harm, and positively contributing to another's good. The best interest principle, based on beneficence, tell us that in making decisions regarding the treatment of incompetents, we should do things in the best interests of those persons (McConnell, 1997).

In this case, Tom was unable to express his thought; it was accepted that parents had authority to make decisions on his behalf. It is assumed that parents have commitment and a profound love towards their child's welfare. They share family, cultural, and religious beliefs with the child; therefore they are best placed to make surrogate decisions on behalf of their child. The doctors' duty of care is to their patients; decisions must be made in the best interests of patients, according to the knowledge of their medical condition at the time (Street, Ashcroft, Henderson \& Campbell, 2000).

Life-sustaining treatment for patients with permanent vegetative state is no longer in their best interests (Street et al., 2000). In Tom's situation, resuscitation only prolonged the dying process and would not produce more medical benefits. To prevent needless suffering, letting him die could be merciful and would promote beneficence. Upon an understanding of the terms well-being and patient's interests, death may be in the patient's interests in some instances (Graham, 1993). In fact, maintaining his life did not promote his wellbeing, but he was forced to continue a life with poor quality. Choosing not to resuscitate him could be defined as morally right because the consequence allowed him to die peacefully with dignity (Jaing et al., 2007; Jones, 2007).

\section{Non-maleficence}

The principle of nonmaleficence says that the moral agent should not harm nor inflict evil on others (McConnell, 1997); everyone has the responsibility to protect all people from harm (Dunn, 1998).

When it is believed that treatment is futile, there is no obligation to treat; and indeed to do so would be considered an assault on the patient (Street et al., 2000).The responsibility not to harm others would oppose performing CPR when its use is inappropriate or its outcomes would cause harm (McDermott, 2002). CPR is a traumatic procedure, even in a successful resuscitation, the patient can suffer severe damage to the lungs, heart, or brain, so death will occur hours or days later, or survival will be in the form of an irreversible coma (Purtilo \& Cassel, 1981). It was an echo to Tom's condition which resulted from a previous CPR. Furthermore, the guidelines from the British Medical Association and the Resuscitation Council stated that CPR should not be attempted when the patient's condition indicates that effective CPR is unlikely to be successful (Sommerville, 1993). Therefore, the adverse effects of CPR were too harmful to Tom and attempting CPR on him was likely to fail; so, the DNR order could avoid doing harm to him.

\section{Autonomy}

Autonomy is the independence to determine an individual's own direction on condition that other's individual liberties are respected
(Dunn, 1998). Patients should be treated as autonomous individuals having the right to voluntarily elect whether to consent to treatments and procedures, including life-sustaining medical care (KagawaSinger \& Blackhall, 2001).

An individual's capacity for autonomous choice could be undermined and be diminished by the defect in the individual's ability to control his desires or actions (McCormark, 1998). Tom was unable to be autonomous because of impaired physical and mental capacities; others might be appropriate to help him make decisions in his best interests. Doctors clearly played an important role in making decisions for him. They understood his medical conditions and had an ethical responsibility to act in Tom's best interests (White, et al., 2007). Parents are the best surrogates in making decisions on the child's behalf (Street et al., 2000). The opinions of the parents were sought regarding Tom's best interests, to agree implementing the DNR order on him, as his parents might know Tom's wishes.

The right to life is inalienable; others have no permission to infringe on that right (McConnell, 1997). Tom had no ability to contribute in the decision making and had no response that his parents were unable to interact with him due to his intellectual level (Street et al., 2000). There was doubt if his parents really knew his wishes? Do all parents make decisions in their child's best interests? Most people considered the patient's own wish as the most important factor in DNR decisions. Therefore, all patients should receive cardiopulmonary resuscitation (CPR) care if the patient's wish was unknown; even if family members refused CPR (Sham et al., 2007; Yap, Joynt \& Gomersall, 2004). Although Tom's parents consented to the DNR order, they had no right to control his life indeed.

\section{Justice}

Justice has been defined as just, fair, equitable, and unbiased decision making which is supposedly in favor of the person in need (Dunn, 1998).

The shortage of critical care beds, the length of hospital stay, and the cost of health care expenses have also been identified as non-medical factors leading to DNR orders (Sanchez-Sweatman \& Carlin, 1997). This tension raises the argument of an individual citizen's right claims on society. There are no constitutional "rights" to unlimited health care. Since end-of-life care necessitates the greatest cost with the least return, to eliminate waste, it is reasonable to begin restricting health-care spending. Rationing is inevitable because it protects the autonomy and availability of fundamental health care to the many most likely to benefit. To justify the expenditure of limited resources, society will choose not to provide CPR for predefined situations in which CPR is unlikely to be successful (Curtis \& Burt, 2007).

In the context of limited resources, the decision to prolong the patient's life via medical intervention may result in others having to forego treatment because of a lack of funding (Trnobranski, 1996). From the utilitarian perspective, the scarce sources should be promoted the greatest good to the greatest number of people so that the value to the society could be maximised. Thus, spending great medical expenditures in extending Tom's dying process was unfair to others.

Arguably, the cost of treatment nevertheless should not be taken into consideration in the DNR decision, whether the cost is paid by the government or the patient. The patient's wish is considered as the highest priority in DNR decisions (Sham et al., 2007). A special relationship exists between healthcare professionals and their patients, and healthcare workers do not have the right to abrogate that relationship merely in order to maximise good for others.

\section{Legal considerations}

A patient has a fundamental right to $C P R$, and medical and nursing staff have a duty to perform it (Costello, 2002). Undertaking CPR when it is against the expressed wishes of the patient could be classed as 
a trespass, while failure to initiate CPR when it is indicated would be classified as negligence (Jevon, 1999). Clear documentation of a DNR order on a designated patient, hence, is very important.

Within the definition of informed consent, a patient and his significant others are advised of the benefits, risks, and alternatives to treatment, along with their right to accept or refuse treatment. Healthcare providers must ascertain the person making the DNR decision has all the relevant information and is aware of the consequences of his/ her decisions (Eckberg, 1998).

\section{Nursing implications}

Individual's perspective is influenced by numerous factors such as gender, personal psychology, and life experiences; culture fundamentally shapes the way people make meaning out of illness, suffering, and dying, and thus also affects how they make use of medical services at the end of life (Kagawa-Singer \& Blackhall, 2001). Nurses should be aware of different patients' needs on making decision about DNR orders.

Good communication is essential in avoiding unnecessary anxiety, misunderstanding, and stress (Jevon, 1999). Training in communication and decision making about DNR orders in healthcare professionals, and public education on the concept of DNR in Hong Kong should be promoted (Thibault-Prevost, Jensen \& Hodgins, 2000; Yap et al., 2004). Nurses can also act as advocates for the patients and families in decision making (Street et al., 2000).

If prolonging life is no longer in a child's best interests and promoting comfort is the primary goal (Henley, 2002), nurses must promote and safeguard the interests and well-being of patients, and also recognise and respect the uniqueness and dignity of each patient. It must be stressed that DNR orders only apply to CPR; all other forms of treatment and care which are appropriate to the patient are not precluded and should not be influenced by DNR orders (Sommerville, 1993).

\section{CONCLUSIONS}

In conclusion, determining how long to extend life or should we exercise a DNR order on a vegetative patient was a difficult, complex, and emotive problem encountered in health care. There was no simple answer to such difficult dilemma. The duty to act in the patient's best interests lies at the heart of caring for the sick and to this end a number of ethical theories embraced. The legal issue must be considered as well. These principles can be applied to end-of-life issues and guide careers to act in accordance with patient's welfare. The well-being and best interests of the patient should always be promoted and safeguarded.

There is no right or wrong answer to Tom's case. On reflection, adhering to one principle can mean other principles are compromised. Some healthcare professionals may consider continuing aggressive treatment to prolong life in the belief that it was in Tom's best interests, whereas others may think prolonging his suffering with poor quality of life was unethical. There was an obvious tension between different healthcare providers' beliefs. Actions are influenced and directed by our personal philosophical viewpoints; it seems imperative for healthcare professionals to carefully examine the ethical perspectives pertinent to a life-death decision. Ethical dilemmas will increase in the future. Critical care nurses must take a proactive approach to obtain answers to these problems.

\section{REFERENCES}

Costello J (2002). Do not resuscitate orders and older patients: findings from an ethnographic study of hospital wards for older people. Journal of Advanced Nursing (39) 5, 491-499.

Curtis JR, Burt RA (2007). Point: the ethics of unilateral "do not resuscitate" orders: the role of "informed assent" [Editorial]. Chest 132 (3), 748-751.

Daly BJ, Gorecki J, Sadowski A, Rudy EB, Montenegro HD, Song $\mathrm{R}$, Dyer MA (1996). Do-not-resuscitate practices in the chronically critically ill. Heart \& Lung 25 (4), 310-317.

Dunn MC (1998). Knowledge helps health care professionals deal with ethical dilemmas. AORN Journal 67 (3), 658-661.

Eckberg $E$ (1998). The continuing ethical dilemma of the do-notresuscitate order. AORN Journal 67 (4), 783-790.

Graham R (1993). Ethics in nursing practice (2nd ed). London: Bailliere Tindall.

Hendrick J (2000). Law and ethics in nursing and health care. Cheltenham: Stanley Thornes.

Henley LD (2002). End of life care in HIV-infected children who died in hospital. Developing World Bioethics 2 (1), 38-54.

Jaing TH, Tsay PK, Fang EC, Yang SH, Chen SH, Yang CP, Hung IJ (2007). "Do-not-resuscitate" orders in patients with cancer at a children's hospital in Taiwan. Journal of Medical Ethics 33 (4), 194-196.

Jevon P (1999) Do not resuscitate orders: the issues. Nursing Standard 13 (40), 45-46.

Jones $\mathrm{J}$ (2007). Do not resuscitate: reflections on an ethical dilemma. Nursing Standard 21 (46), 35-39.

Kagawa-Singer M, Blackhall LJ (2001). Negotiating cross-cultural issues at the end of life: "You got to go where he lives". JAMA 286 (23), 2993-3001.

McConnell TC (1997). Moral issues in health care: an introduction to medical ethics ( 2 nd ed). Belmont: Wadsworth Publishing Company.

McCormack P (1998). Quality of life and the right to die: an ethical dilemma. Journal of Advanced Nursing 28 (1), 63-69.

McDermott A (2002) Involving patients in discussions of do-notresuscitate orders. Professional Nurse (17) 8, 465-468.

Purtilo RB, Cassel CK (1981). Ethical dimensions in the health professions. Philadelphia: W. B. Saunders Conmpany.

Roth R, Corrigan A (2005). Do not resuscitate (DNR) policy. Henry County Health Center Mt. Pleasant, lowa.

Sanchez-Sweatman LR, Carlin K (1997). CPR. Who decides? The Canadian Nurse 93 (4), 31-34.

Sham CO, Cheng YW, Ho KW, Lai PH, Lo LW, Wan HL, Wong CY, Yeung YN, Yuen SH, Wong AY (2007). Do-not-resuscitate decision: the attitudes of medical and non-medical students. Journal of Medical Ethics 33 (5), 261-265.

Simpson SH (1994). A study into the uses and effects of do-notresuscitate orders in the intensive care units of two teaching hospitals. Intensive \& Critical Care Nursing 10 (1), 12-22.

Street K, Ashcroft R, Henderson J, Campbell AV (2000). The decision making process regarding the withdrawal or withholding of potential life-saving treatments in a children's hospital. Journal of Medical Ethics 26 (5), 346-352.

Sommerville A (1993). Medical ethics today: its practice and philosophy. London: BMJ Publishing Group.

Thibault-Prevost J, Jensen LA, Hodgins M (2000). Critical care nurses' perceptions of DNR status. Journal of Nursing Scholarship 32 (3), 259-265.

Thompson IE, Melia KM, Boyd KM, Horsburgh D (2006). Nursing ethics (5th ed). Edinburgh: Churchill Livingstone Elsevier.

Trnobranski PH (1996). The decision to prolong life: ethical perspectives of a clinical dilemma. Journal of Clinical Nursing 5 (4), 233-240. 
White DB, Curtis JR, Wolf LE, Prendergast TJ, Taichman DB, Kuniyoshi G, Acerra F, Lo B, Luce JM (2007). Life support for patients without a surrogate decision maker: who decides? Annals of Internal Medicine 147 (1), 34-40.
Yap HY, Joynt GM, Gomersall CD (2004). Ethical attitudes of intensive care physicians in Hong Kong: questionnaire survey. Hong Kong Medical Journal 10 (4), 244-250. 